Revista do Departamento de Geografia
Universidade de São Paulo
www.revistas.usp.br/rdg
ISSN 2236-2878

\title{
AVANÇO E RETRAÇÃO DE ÁREA GLACIAL NO EXTREMO NORTE DA PENÍNSULA TRINITY, ANTÁRTICA, ENTRE 1988 E 2015
}

\author{
ADVANCE AND RETREAT OF GLACIERS IN THE NORTHERN \\ TIP OF THE TRINITY PENINSULA, ANTARCTICA, 1988-2015
}

\author{
Maria Eliza Sotille \\ Universidade Federal do Rio Grande do Sul \\ maria.sotille@ufrgs.br \\ Ulisses Franz Bremer \\ Universidade Federal do Rio Grande do Sul \\ Jefferson Cardia Simões \\ Universidade Federal do Rio Grande do Sul
}

Recebido (Received): 22/09/2015 Aceito (Accepted): 27/01/2016

DOI: http://dx.doi.org/10.11606/rdg.v31i0.104513

Resumo: O extremo norte da Península Trinity, na Península Antártica, sofreu mudanças na sua área coberta de gelo e na temperatura do ar ao longo das últimas três décadas. Visando apontar os avanços e as retrações da massa de gelo ocorridas na área, realizamos um levantamento das variações da posição das frentes de 32 geleiras ao longo de 27 anos (1988-2015). O estudo usou 10 imagens Landsat para identificar as variações das frentes das geleiras e compará-las com as variações na temperatura média anual do ar. Nesse período, ocorreu o recuo de aproximadamente $50 \mathrm{~km}^{2}$ nas frentes de gelo da região e um avanço de $\pm 10 \mathrm{~km}^{2}$, resultando na perda de $\pm 40 \mathrm{~km}^{2}$ da área coberta por gelo no extremo norte da Península Trinity (em torno de $\pm 2,7 \%$ da área de estudo). No período 1988-2000 essa península perdeu $\pm 25,1 \mathrm{~km}^{2}$ de gelo somente em suas frentes, entre 2000 e 2006 a perda for de $\pm 12,2 \mathrm{~km}^{2}$ e entre 2006 e $2011 \mathrm{de} 5,0 \mathrm{~km}^{2}$. O período 2011-2015 foi o único a apresentar avanços maiores que retrações, com um aumento de $\pm 2,5 \mathrm{~km}^{2}$ $( \pm 0,16 \%)$ de área. Os dados da temperatura média do ar, provenientes da base antártica Esperanza (Argentina $63^{\circ} 23^{\prime} \mathrm{S} 56^{\circ} 59^{\prime} \mathrm{O}$ ), obtidos no portal READER, mostram aumento na média durante o verão (dez-fev) ao longo dos últimos 30 anos (1985-2015), no período 1964-2014 esse aumento foi de $1,45^{\circ} \mathrm{C}$.

Palavras-Chave: Deglaciação, geleiras, áreas livres de gelo, Antártica.

\begin{abstract}
The north tip of the Trinity Peninsula, Antarctic Peninsula, has undergone changes in its ice-covered area and in the air temperature over the last three decades. Aiming to identify ice mass advances and retractions that occurred in the area, we conducted a survey of the changes in the ice front positions of 32 glaciers over 27 years (1988-2015). The study used 10 Landsat images to identify variations of glaciers fronts and compare them with variations in the mean annual air temperature. During this period, there was a decrease of approximately $50 \mathrm{~km}^{2}$ in the regional ice fronts and an increase of \pm 10 $\mathrm{km}^{2}$, resulting in the loss of $\pm 40 \mathrm{~km}^{2}$ of the ice-covered area at the north tip of the Trinity Peninsula (around \pm $2.7 \%$ of the study area). In the period 1988-2000 this peninsula lost $\pm 25.1 \mathrm{~km}^{2}$ of ice only in their fronts, from 2000 to 2006 the loss was of $\pm 12.2 \mathrm{~km}^{2}$ and $5.0 \mathrm{~km}^{2}$ from 2006 to 2011. The 2011-2015 period was the only one to show advances greater than retreats, with an area increase of $\pm 2.5 \mathrm{~km}^{2}( \pm 0.16 \%)$. The mean air temperature data from the Antarctic base Esperanza (Argentina, 6323'S 56 59'O), obtained from the READER portal, show an increase in the summer for the past 30 years (1985-2015), in the 1964-2014 period the increase was $1.45^{\circ} \mathrm{C}$.
\end{abstract}

Keywords: Deglaciation, glaciers, ice-free areas, Antarctica 


\section{INTRODUÇÃO}

A Península Antártica (PA) é o setor mais quente da Antártica apresentando tendência de aquecimento regional consistente (VAUGHAN et al., 2001). Estima-se que a temperatura atmosférica superficial da região tenha aumentado desde 1950. Turner et al., (2005) e Vaughan et al. (2003) apontam um aumento da temperatura média do ar de cerca de $2,8^{\circ} \mathrm{C}$ - sendo que as maiores tendências de aquecimento ocorrem nas partes oeste e norte da península (TURNER et al., 2009).

Durante os anos $1958-2000$ o aquecimento na costa oeste da PA chegou a $0,63^{\circ} \mathrm{C} / 10$ anos na estação Rothera e $0,67^{\circ} \mathrm{C} / 10$ anos na estação Faraday. No extremo norte foi observado um aumento ligeiramente menor, de $0,42^{\circ} \mathrm{C} / 10$ anos na estação Esperanza (KEJNA, 2003). As consequências desta mudança climática incluem a desintegração de plataformas de gelo, retrações de geleiras, mudanças nos sistemas glaciais e alterações no meio biótico da região (VAUGHAN et al., 2001).

O derretimento da neve e do gelo contribui para a elevação do nível médio dos mares e para variações climáticas, estima-se que forças motrizes subjacentes desses processos podem gerar mudanças nos padrões de circulação dos oceanos, nos sistemas de pressão atmosférica, além do aumento da temperatura média global (VAUGHAN et al., 2001).

Na península Trinity, norte da península Antártica, recuos significativos foram encontrados, Davies et al. (2012) apontam retrações de $-4,55 \%$ nas geleiras da costa leste da península Trinity entre 1988-2001, e -2,6\% na costa oeste, com 90\% das geleiras da região em retração no período.

Apesar dos avanços e recuos de diferentes geleiras estarem, em geral, de maneira síncrona, diferenças nos climas locais podem ser responsáveis por algumas das diferenças de comportamento. A reação de uma geleira a uma mudança de clima depende do seu regime de escoamento além de outros fatores, como a velocidade do vento, umidade, nuvens, nevascas, características de superfície e outras variáveis. Assim, pode-se dizer que o processo de deglaciação está vinculado à integração de uma grande gama de parâmetros (CUFFEY e PATERSON, 2010).

Visando apontar e compreender as mudanças ocorridas nas massas de gelo no extremo norte da Península Trinity, na Antártica, foi realizado o monitoramento, através de análise multiespectral de imagens de satélite, das geleiras da área, relacionando as variações glaciais às variações interanuais da temperatura média do ar para a região.

\section{ÁREA DE ESTUDO}

A área de estudo (Figura 1), situa-se no extremo norte da Península Trinity, a nordeste do platô Laclavère, entre as latitudes $63^{\circ} 14^{\prime}$ e $63^{\circ} 39^{\prime}$ Sul e longitudes $56^{\circ} 59^{\prime}$ e $57^{\circ} 37^{\prime}$ Oeste. A área conta com 32 bacias de drenagem e possui $1.450 \mathrm{~km}^{2}$. A área engloba a península Tabarin, a baía Duse e a baía Esperança, e abriga as bases antárticas Esperanza (Argentina) a $63^{\circ} 23^{\prime} \mathrm{S}$ e $56^{\circ} 59^{\prime} \mathrm{O}$ e ECARE (Uruguaia) a 63⒉'S e 56 59'O. A região diferencia-se do resto da península por possuir altitude média muito menor - cerca de $500 \mathrm{~m}$, conforme o modelo digital de elevação do NSIDC (2012). Predominam características de relevo suave ondulado e, a exemplo do continente, a maior parte da área é coberta por neve e gelo.

\section{PROCEDIMENTOS METODOLÓGICOS}

\section{Análise de dados de sensoriamento remoto orbital}

Foram utilizadas 8 cenas do Landsat (sensores TM, ETM+e OLI/TIRS) entre os anos de 1988 e 2015 (Fig. 2), adquiridas através do Visualizador Global do Serviço Geológico dos Estados Unidos (USGS GloVis). Foram adquiridas imagens adicionais em anos específicos visando contornar a cobertura de nuvens e as linhas de falha do sensor ETM+, que a partir de 2003 passou a apresentar falhas de dados nas imagens devido a uma falha no espelho corretor de linha (SLC), sendo, porém, ainda úteis, e mantendo as mesmas correções radiométricas e geométricas. Foram adquiridas imagens apenas do período de ablação (período de derretimento de gelo), potencializado durante os meses de dezembro e fevereiro. 


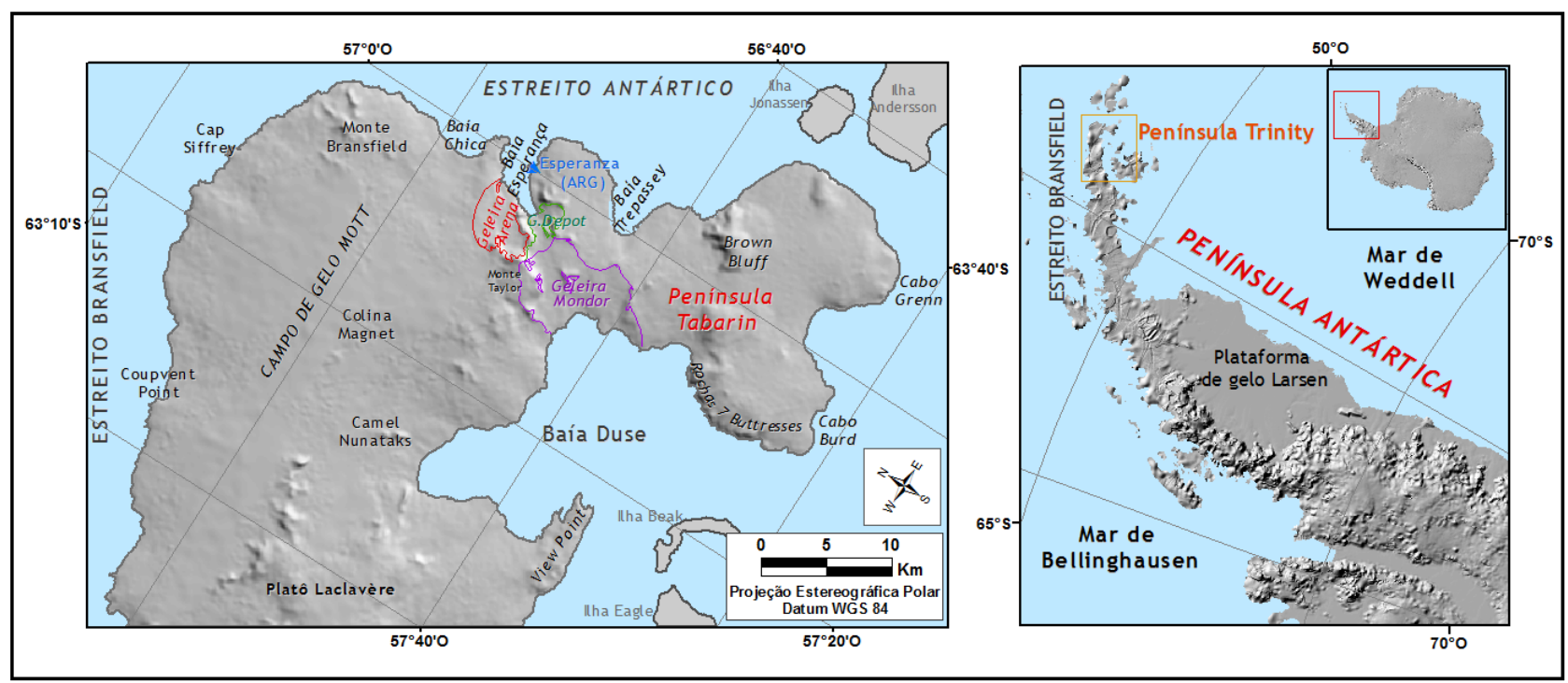

Figura 1: Localização da área de estudo com destaque para a localização da península Trinity na Península Antártica; no detalhe, mapa do continente antártico.

O pré-processamento das imagens passou por etapas de fusão de bandas, mosaicagem, reprojeção, recorte da área de estudos e correção das linhas relativas à falha do sensor, através de sobreposição de cenas e correção cosmética utilizando informações dos pixels vizinhos. O georreferenciamento foi realizado através do co-registro de imagens, utilizando como base para o registro das imagens uma cena do Landsat $7 \mathrm{ETM}+$, de 29 de fevereiro de 2000, georreferenciadas a mesma imagem pertencente Mosaico de Imagens Landsat da Antártica (LIMA). Foram selecionados uma série de 20 pontos de controle de fácil identificação, restritos às áreas livres de gelo e distribuídos por toda a área de estudo, além de ilhas vizinhas. Os valores de RMS (Erro Médio Quadrático por pixel) de cada imagem foram menores que 0,50 .

\section{Obtenção das frentes das geleiras}

A delimitação das frentes de geleiras foi obtida através de classificação de imagens RGB 321 dos anos 1988, 2000, 2006, 2011, 2014, 2015. Foi realizada uma classificação não supervisionada por meio de um ISO CLUSTER, que realiza uma seleção dos pixels pelos picos dos histogramas, e, quando identificados, todos os possíveis valores são associados ao pico mais próximo, sendo que as classes tendem a cair no ponto médio entre os picos (EASTMAN, 2006). A classificação não supervisionada não requer amostras das classes de interesse, sendo definida apenas a quantidade de classes a serem geradas. Assim, foram estabelecidas 2 classes de interesse: neve/gelo e oceano. As classificações foram realizadas no software ArcMap 10.2 através das ferramentas do Spatial Analyst: Iso Cluster Unsupervised Classification, e os valores obtidos no índice Kappa foram de 0,71, 0,81, $0,73,0,90,0,85,0,80$.

As classificações passaram pela aplicação de uma filtragem através do "Filtro Predominante" (Majority Filter) do ArcMap 10.2, que visa suavizar e eliminar dados errôneos da cena ao reduzir o número de pixels isolados e foram transformadas em vetores. Correções manuais foram realizadas nas linhas de costa utilizando imagens NDSI para auxiliar na delimitação dos alvos, e a banda do SWIR, para identificar e discriminar as áreas com nuvens. Nas imagens com stripes as linhas de costa foram corrigidas utilizando-se 2 imagens de cada ano, sobrepostas nas linhas de falhas.

As áreas foram medidas em quilômetros quadrados $\left(\mathrm{km}^{2}\right)$, com base nos arquivos vetoriais e a criação de polígonos de costa para cada intervalo (1988, 2000, 2006, 2011, 2015) possibilitou a obtenção da área para cada um dos anos investigados. As variações ao longo do intervalo (áreas de avanço e retração) foram adquiridas através da ferramenta "Apagar" (Erase) do ArcMap 10.2. Essa técnica cria uma feição ao sobrepor um polígono de entrada a um polígono com características a serem apagadas, assim, somente as áreas externas do polígono de entrada (que não se enquadram nas características a serem apagadas) são copiados para a feição de saída. Dessa forma, ao sobrepor um 
polígono de costa de um ano a um polígono de costa de um ano seguinte obtém-se apenas as áreas que retraíram, já o contrário obtém as áreas que avançaram.

Á área das geleiras foi obtida através da união das linhas de costa de cada ano aos limites internos das bacias de drenagem, já mapeados e disponibilizados na forma de vetores pelo Comitê Científico de Pesquisa Antártica (SCAR) em sua Base Digital de Dados Antárticos (ADD). Foi atribuído um número para cada geleira.

\section{Análise de dados climáticos}

Verificou-se médias mensais de temperatura do ar da área para o período de 1985-2015 e 1964-2014, obtidas através do projeto READER (Reference Antarctic Data for Environmental Research) do SCAR, dados estes provenientes, na grande maioria, da base antártica Esperanza.

Os dados foram organizados em tabelas onde calculou-se a média para o período total e para cada mês do verão, que se estende de dezembro a fevereiro. Foram gerados gráficos com o comportamento das médias onde foram acrescentadas linhas de tendência linear e de média móvel, sendo que a linha de tendência linear geralmente mostra que algo está aumentando ou diminuindo a uma taxa fixa; já a linha de tendência de média móvel suaviza as flutuações dos dados, de modo a mostrar um padrão ou uma tendência com maior clareza.

Foram ainda gerados gráficos com as temperaturas médias dos meses de janeiro e fevereiro para os anos de 1988, 2000, 2006, 2011 e 2015, condizentes com o período das imagens de satélite, interpretando as variações nos dados de temperatura do ar com as variações glaciais da área no intervalo.

\section{RESULTADOS}

A classificação não supervisionada obteve resultados satisfatórios para as imagens de 1988, 2000, 2006, 2011-1 e 2014. A técnica permitiu a delimitação automática da linha de costa em grandes regiões das imagens, sendo que falhas se deram em função das áreas livres de gelo e áreas de sombra. Nas imagens dos anos de 2011-2 e 2015, com presença de pluma de gelo, o mesmo método foi aplicado, porém, não foi possível a delimitação da costa nessas áreas específicas, sendo necessária uma classificação supervisionada nessas imagens para auxiliar na distinção entre as feições neve/gelo e pluma de sedimentos. Ainda, pequenas correções manuais foram necessárias nas classificações. Com as classificações obtiveram-se os polígonos de costa para cada um dos 5 anos das imagens.

\section{Variações de frente de gelo no extremo norte da Península Trinity}

Uma significativa variação glacial foi detectada na área nos últimos anos (Figura 2). Entre o 1988-2000 a área perdeu $\pm 25,1 \mathrm{~km}^{2}$ de gelo somente em suas frentes, nota-se que este é o maior intervalo das investigações, período de 12 anos. Na sequência dos anos, em investigações com intervalos mais curtos, a área continuou a diminuir, sendo que entre 2000-2006 o recuo foi de $\pm 12,2$ $\mathrm{km}^{2}$, e entre 2006-2011 de $\pm 5,0 \mathrm{~km}^{2}$. Diferentemente, no período entre 2011-2015, a área avançou ganhando $\pm 2,5 \mathrm{~km}^{2}$ de massa.

Em termos de área, o recuo total entre $1988-2015$ foi de $\pm 39,8 \mathrm{~km}^{2}$, representando uma retração de $\pm 2,7 \%$ nas frentes de geleira da área, sendo, $\pm 1,7 \%$ em $1988-2000, \pm 0,83 \%$ entre 2000 2006, $\pm 0,34 \%$ em 2006-2011, e um aumento de $\pm 0,17 \%$ em 2011-2015.

Na Península Tabarin, além das geleiras conhecidas da região, pode-se destacar outras 4 áreas que apresentaram consideráveis mudanças em suas frentes (Figura 3), e que se referem às geleiras $12,13,15,16,17,18$ e 24 .

Nos arredores do Brown Bluff, as duas geleiras apresentaram tendências de recuo, tendo a geleira 12 perdido $\pm 9 \%$ e a geleira $13, \pm 7 \%$ de sua área. As 4 geleiras na faixa entre o Cabo Green e o Cabo Burd também apresentaram comportamento de retração, com diminuição de $\pm 4 \%, \pm 6 \%, \pm 20 \%$ 
e $\pm 13 \%$ nas geleiras $15,16,17$ e 18 , respectivamente, para o período 1988-2015. Ao lado do rochedo 7 Butresses a geleira 24 apresentou $\pm 7 \%$ de retração em suas frentes. Em combinação, essas 7 geleiras perderam $\pm 17,66 \mathrm{~km}^{2}$ de área, uma diminuição de $\pm 6,9 \%$.

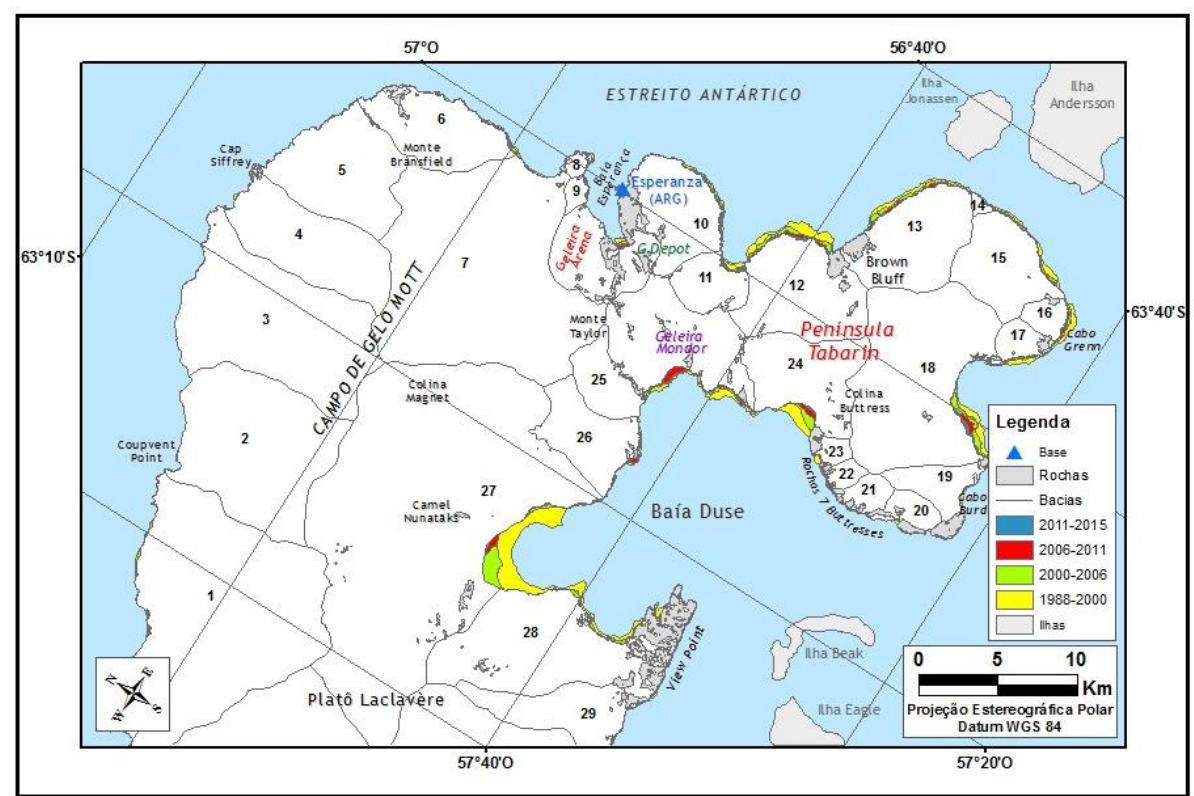

Figura 2: Variações nas frentes de gelo do extremo norte da península Trinity
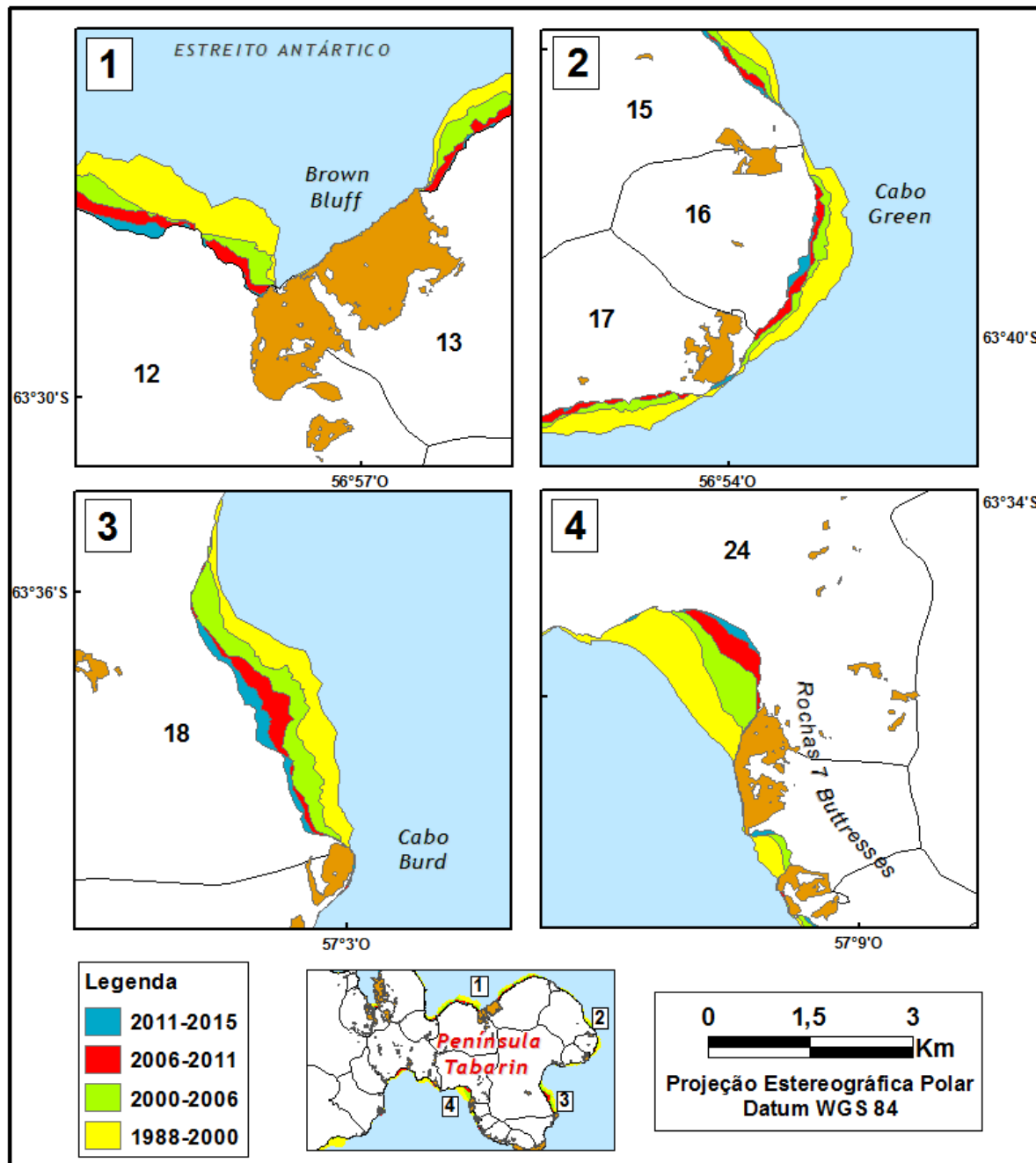

Figura 3: Variações nas frentes de gelo na península Tabarin. 
Na área da baía Duse, próximo a View Point, foram observadas retrações em três das 4 geleiras alimentadas pelo campo de gelo Mott $(25,26,27,28)$. Nas geleiras 26 e 27 as perdas foram de \pm 14 $\mathrm{km}^{2}(3 \%)$, sendo que a geleira 27 apresentou pouca variação no período de 2006-2015, com as retrações ocorrendo anteriormente. Na geleira 28 o recuo foi de $\pm 6 \%$ de sua área, e na geleira 25 foi constatado um pequeno avanço.

\section{Dinâmica de avanço e retração das geleiras Arena, Depot e Mondor}

A geleira Arena (Figura 4) foi a geleira que apresentou as menores taxas de variações ao longo dos últimos 27 anos quando comparada as geleiras Depot e Mondor. A área da geleira variou levemente durante os anos investigados, recuando de $\pm 16,18 \mathrm{~km}^{2} \mathrm{em} 1988$ para $\pm 16,13 \mathrm{~km}^{2} \mathrm{em} 2015$. Os resultados mostram uma perda de área de $\pm 0,6 \%$ dentro do período de 18 anos de retração, e um ganho de $\pm 0,3 \%$ de área dentro do período de 9 anos de avanço, sendo a variação total da geleira de $\pm 0,3 \%$ de perda.

A geleira Depot apresentou um comportamento de recuo no período investigado, perdendo nos últimos 27 anos em torno de $\pm 6,8 \%$ de área, somente em suas frentes. A geleira retraiu de $\pm 6,60$ $\mathrm{km}^{2}$ em 1988 para $\pm 6,15 \mathrm{~km}^{2} \mathrm{em} 2015$. Os intervalos de retração da geleira são de $\pm 2,58 \%$ entre 1988 $2000, \pm 1,71 \%$ no período de $2000-2006, \pm 1,74 \%$ em $2006-2011$ e $\pm 0,97 \%$ entre 2011-2015. Ao comparar intervalos de tempo equivalentes, verifica-se que uma retração entre 1988 a 2000 de $\pm 2,6 \%$, praticamente idêntica à retração entre 2006-2015, de $\pm 2,7 \%$, e semelhante à retração no período de 2000 a 2011, de $\pm 3,4 \%$. Esses dados apresentam tendências de retração para essa geleira em uma escala temporal de décadas.

Na Geleira Mondor o comportamento de retração foi consideravelmente mais expressivo quando comparado ao comportamento de avanço, tendo como resultado uma diminuição da geleira de $\pm 3,22 \mathrm{~km}^{2}$ entre os anos de 1988 a 2015, sendo que esse valor representa uma diminuição de $\pm 7 \%$ da área vigente em 1988, quando era de $\pm 46 \mathrm{~km}^{2}$, tendo recuado para $\pm 42,78 \mathrm{~km}^{2} \mathrm{em} 2015$.

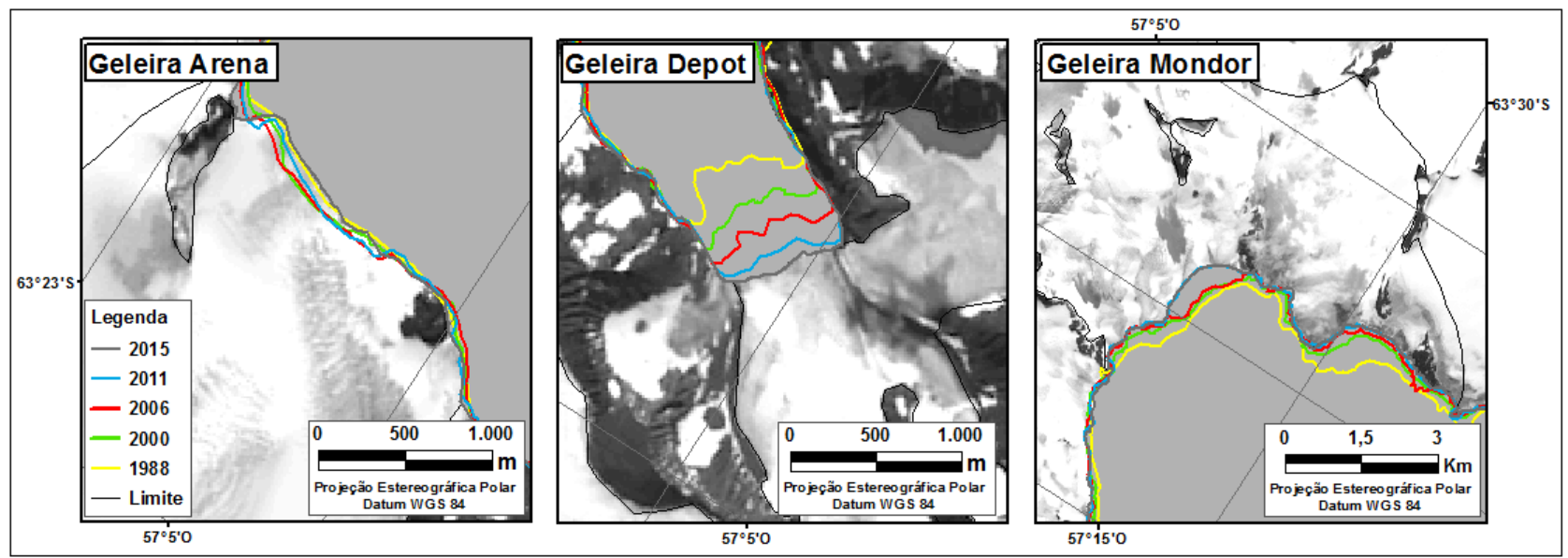

Figura 4: Variações nas frentes de gelo das geleiras Arena, Depot e Mondor

\section{Variações na temperatura do ar da região}

No período das imagens de satélite, de dezembro a fevereiro, onde as temperaturas na PA são frequentemente acima dos $0^{\circ} \mathrm{C}$ (BARRAND et al., 2013), observou-se temperaturas médias predominantemente na faixa de $-0,5$ a $2^{\circ} \mathrm{C}$ em Esperanza (Figura 5) entre 1985 e 2015. Uma verificação mês a mês mostrou diminuição da temperatura média do ar de $-0,13^{\circ} \mathrm{C} / 10$ anos para o mês de dezembro, e aumentos de $0,18^{\circ} \mathrm{C} / 10$ anos para janeiro e $0,13^{\circ} \mathrm{C} / 10$ anos para fevereiro. $\mathrm{Na}$ média dos três meses, nota-se um aumento da temperatura de $0,06^{\circ} \mathrm{C} / 10$ anos. 


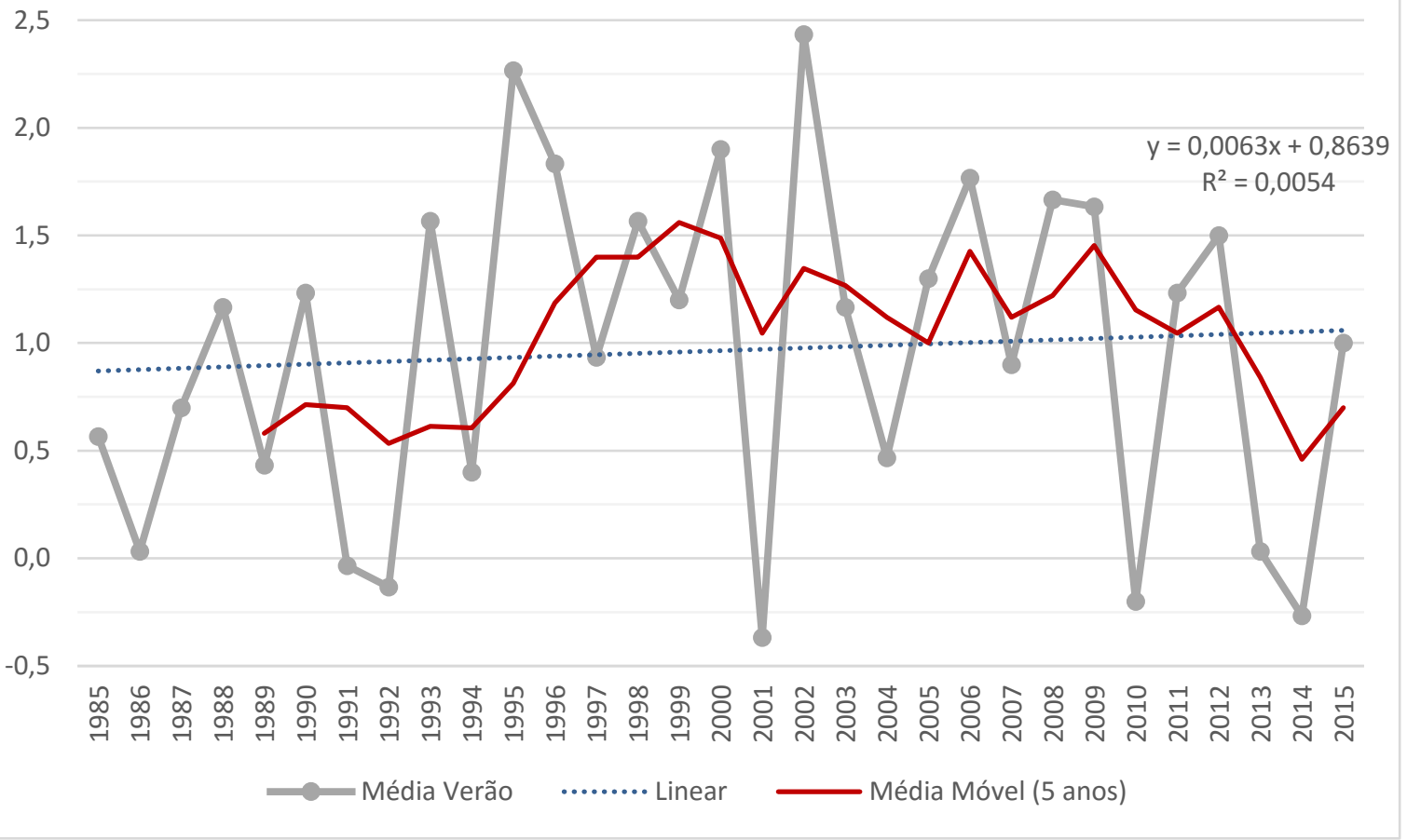

Figura 5: Variações das temperaturas de verão na base Esperanza entre 1988-2015

Uma investigação de tendência de temperatura utilizando intervalo de 50 anos (1964-2014) apresentou aumentos de $0,35^{\circ} \mathrm{C} / 10$ anos para o período do verão (Figura 6), e $0,29^{\circ} \mathrm{C} / 10$ anos para o ano todo, números condizentes com outros estudos, como o de Kejna (2003), que encontrou tendências de $0.42^{\circ} \mathrm{C} / 10$ anos entre $1958-2000$ para Esperanza.

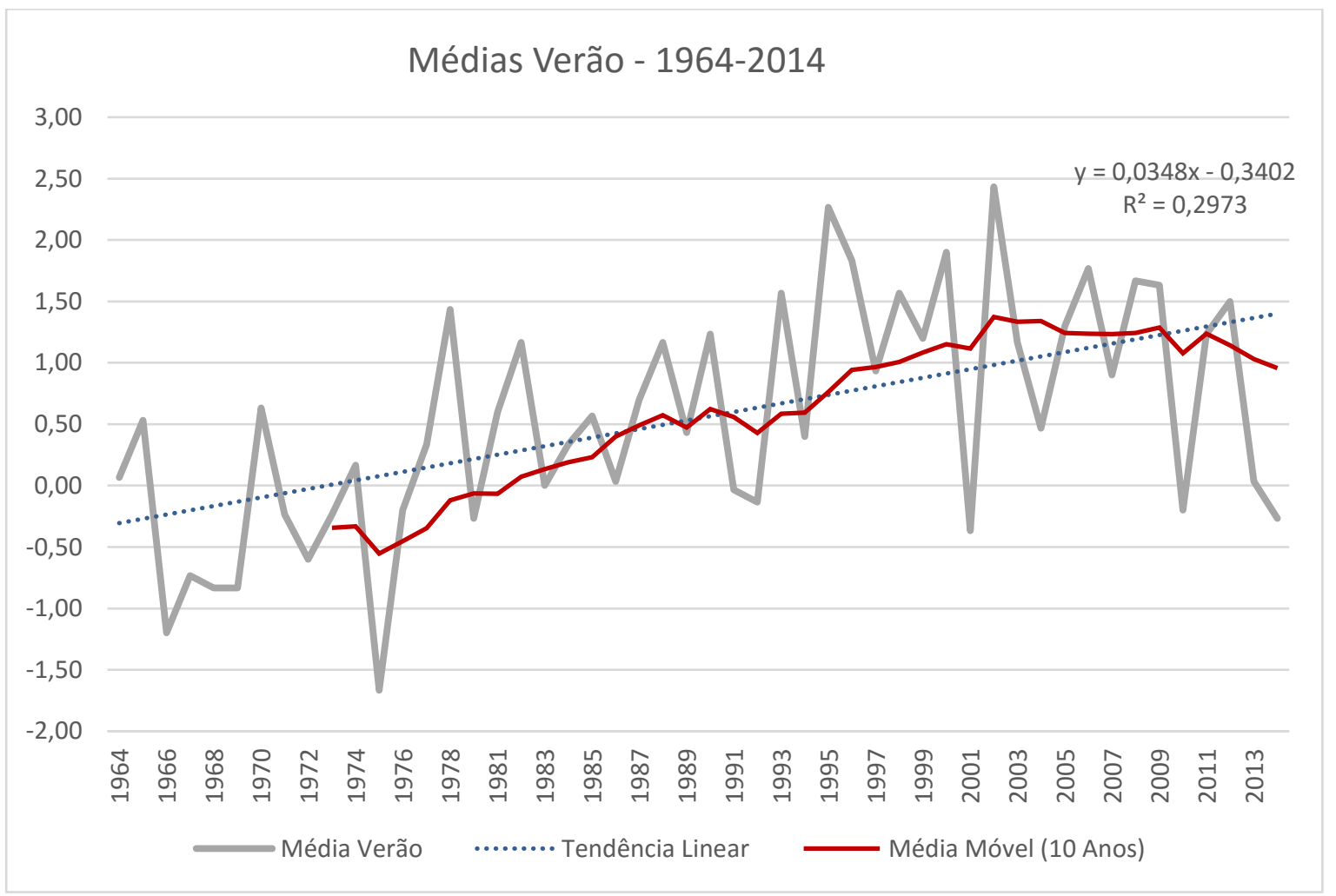

Figura 6: Variações das temperaturas de verão na base Esperanza entre 1964-2014 


\section{DISCUSSÃO}

Os resultados encontrados apresentam taxas de retração significativamente maiores que as de expansão para a área no período de 1988 a 2015, sendo que os valores obtidos para a retração da área foram de aproximadamente $50 \mathrm{~km}^{2}$, enquanto os avanços foram de aproximadamente $10 \mathrm{~km}^{2}$ (Figura 7).

Entre 1988 e 2006 foi o período de maior taxa de recuo de frente das geleiras do norte da Península Antártica, sendo que esse período de quase 20 anos representou aproximadamente $80 \%$ da retração ocorrida. Já o período 2006-2015 foi responsável por aproximadamente $75 \%$ dos avanços encontrados.

Os valores apresentados mostram uma tendência geral de retração das geleiras no norte da Península Antártica, sendo que os resultados confirmam tendências relatadas em estudos anteriores em áreas próximas a Hope Bay, como nas ilhas Shetland do Sul (SIMÕES et al., 1999) e na ilha James Ross (SKVARCA et al., 1997). Observa-se também que, apesar da área como um todo apresentar taxas altas de recuo, taxas de avanço também foram observadas, principalmente na porção norte/noroeste da área, que permaneceu praticamente inalterada. Essas geleiras, expostas ao Estreito Bransfield, apresentam retrações e avanços menores nas suas frentes do que as geleiras a sul/sudeste expostas ao setor do Mar de Weddell (Figura 8).

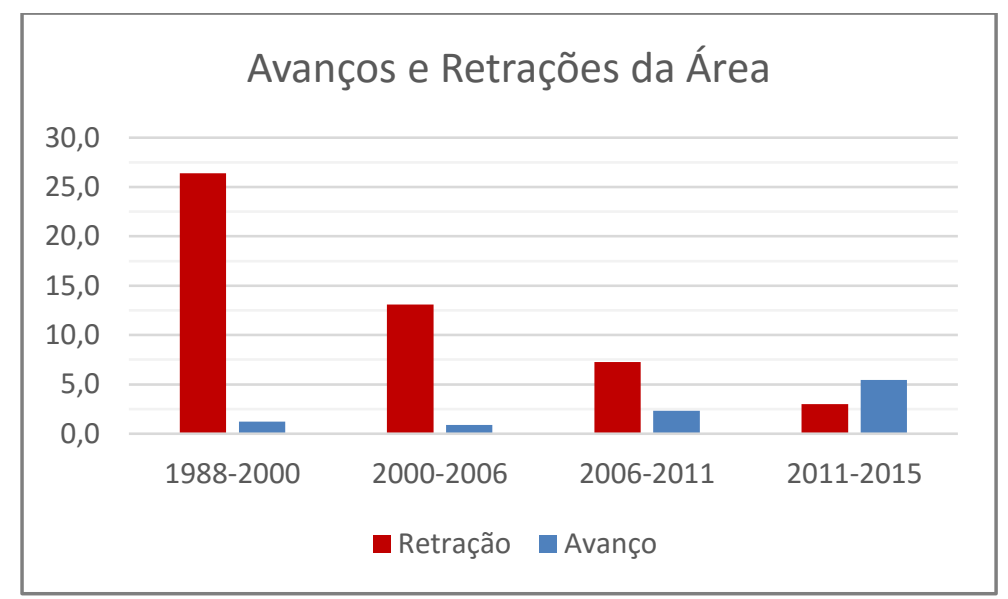

Figura 7: Avanços e retrações de área glacial no extremo norte da Península Antártica

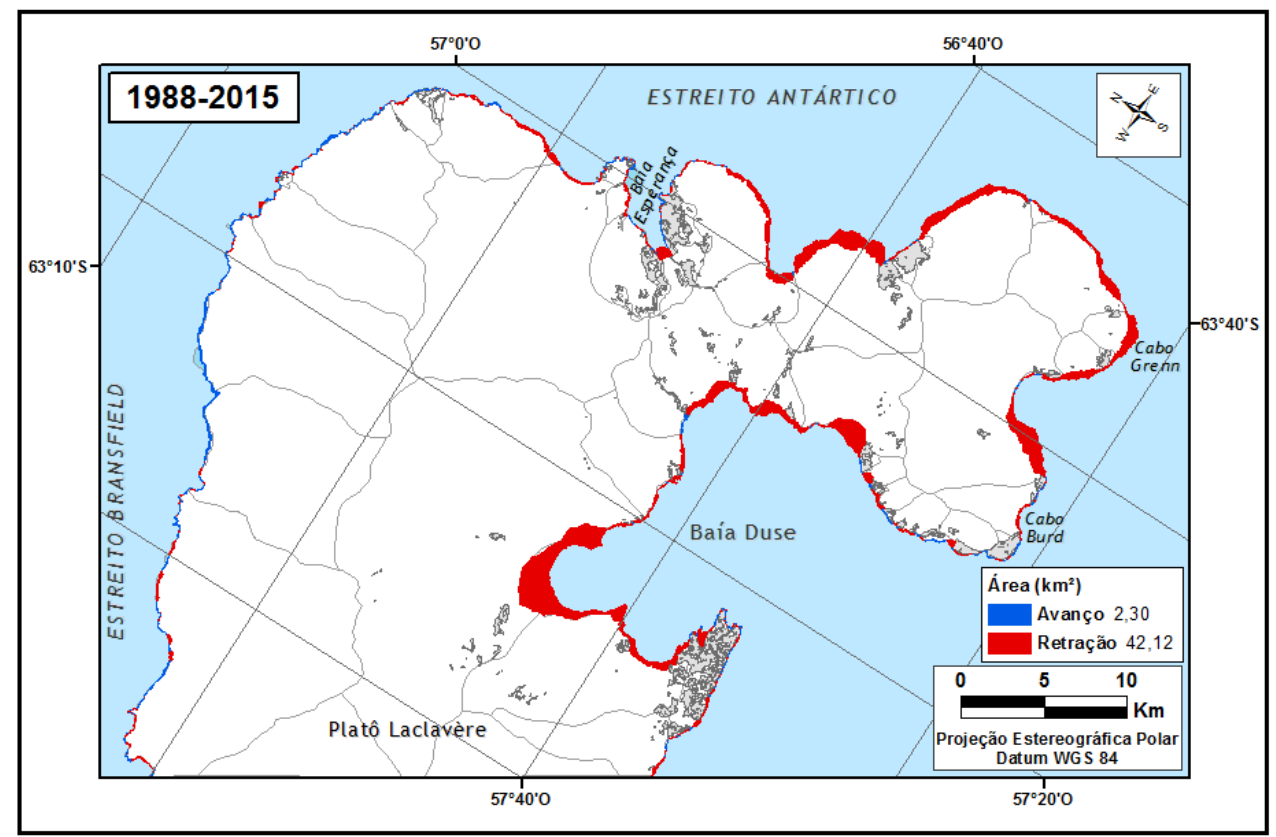

Figura 8: Espacialidade das mudanças no extremo norte da península Trinity entre 1988 e 2015 
A diminuição da área no período 1988-2006 vem em conjunto com um aumento expressivo das médias de temperatura para os meses das imagens de satélite utilizadas (Figura 9). Já para o período 2006-2011 passa-se a verificar uma diminuição de temperatura, com a área diminuindo levemente, e em 2015 com uma diminuição maior na média da temperatura do ar observa-se um avanço de área. Porém, as geleiras que possuem suas frentes no mar têm uma dinâmica associada à ação marinha e apresentam respostas mais complexas às mudanças (PFEFFER, 2003), assim, à medida que são influenciadas por outros fatores externos, como o aquecimento da superfície nos mares (MEREDITH e KING, 2005), padrões de circulação oceânica e aumento no acúmulo de precipitação e neve (TURNER et al., 2005, THOMAS et al., 2008), considera-se difícil isolar uma causa clara do recuo.

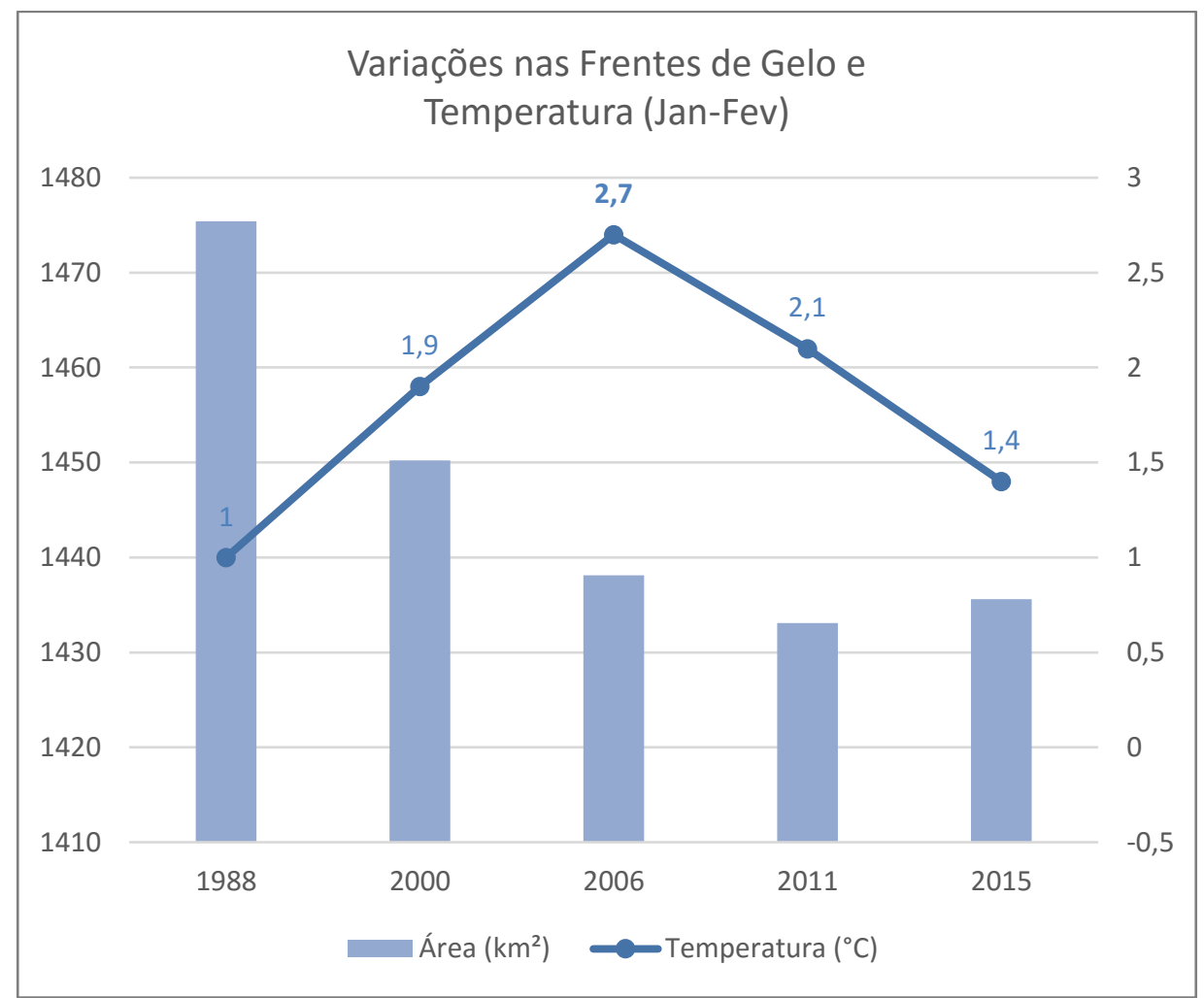

Figura 9: Variações das áreas glaciais e a média de temperatura dos meses de janeiro e fevereiro.

\section{CONCLUSÃO}

Através dos dados do satélite Landsat e da metodologia empregada foi possível verificar as mudanças ocorridas na área glacial da região entre 1988 e 2015. A obtenção das linhas de frente das geleiras, em conjunto com os limites disponibilizados pelo ADD, possibilitou apontar o comportamento e as taxas de variação para cada geleira nos intervalos investigados.

A verificação dos dados de temperatura auxiliou na discussão dos resultados, pois com o conhecimento do comportamento da temperatura do ar foi possível apontar relações entre as mudanças de temperatura e as mudanças da área glacial. Seria, porém, interessante a obtenção de dados diários de temperatura, podendo verificar a quantidade de dias com temperaturas acima de $0^{\circ} \mathrm{C}$ dentro do período do verão.

Considera-se que a retração apontada na área seja o provável resultado de uma combinação de fatores, possivelmente do aquecimento atmosférico, da intensificação do derretimento do gelo, da elevação da temperatura das águas do oceano e da diminuição da espessura e duração do gelo marinho. 


\section{REFERÊNCIAS}

ADD. SCAR Antarctic Digital Database. Version 6.0. In:http://www.add.scar.org 2013.

BARRAND, N.E.; Vaughan, D.G.; Steiner, N.; Kuipers Munneke, P.; van den Broeke, M.R.; Tedesco, M.; Hosking, J.S. Trends in Antarctic Peninsula surface melting conditions from observations and regional climate modeling. Journal of geophysical research. Earth Surface, v. 118, p. 1-16. 2013

CUFFEY, K. M. e PATERSON, W. S. B. The Physics of Glaciers. Oxford, Elsevier Science, $4^{\mathrm{a}}$ edição, p. 740. 2010.

DAVIES, B.J.,Carrivick, J.L., Glasser, N.F., Hambrey, M.J., \& Smellie, J.S., 2012. Variable glacier response to atmospheric warming, northern Antarctic Peninsula, 1988-2009. The Cryosphere v. 6, p. 1031-1048. 2012.

EASTMAN, J.R. Idrisi 15: The Andes Edition. Worcester, MA: Clark University, 2006.

Intergovernmental Panel on Climate Change (IPCC). Climate Change 2013: The physical science basis: Working group I contribution to the fifth assessment report of the Intergovernmental Panel on Climate Change. Cambridge University Press, 2014.

KEJNA, M. Trends of air temperature of the Antarctic during the period 1958-2000. Polish Polar Research, v. 24, p. 99-126. 2003

MEREDITH M.P, King J.C. Rapid climate change in the ocean west of the Antarctic Peninsula during the second half of the 20th century. Geophys. Res. Lett. 32. L19604. 2005

NSIDC (National Snow \& Ice Data Center). Antarctic Peninsula $100 \mathrm{~m}$ digital elevation model derived from ASTER GDEM, version 1. In: http://nsidc.org/data/nsidc-0516.html. 2012

PFEFFER, W.T. 2003. Tidewater glaciers move at their own pace. Nature, 426(6967), 602.

SKVARCA. P., RACK. W., ROTT, H. \& IHARZIHAL \& DONINGELO. T. Evidence of recent climatic warming on the eastern Antarctic Peninsula. Ann. Glaciol. 27. 628-632. 1997

SIMÕES, J.C., BREMER, U.F., AQUINO, F.E. \& FERRON, F.E. Morphology and variations of glacial drainage basins in King George Island icefield, Antarctica. Annals of Glaciology, 29: 220-224. 1999

THOMAS, E. R., MARSHALL G. J., \& MCCONNELL J. R. A doubling in accumulation in the western Antarctic Peninsula since 1850. Geophys. Res. Lett., 35. L01706. 2008

TURNER, J., BINDSCHADLER, R. A., CONVEY, P., DI PRISCO, G., FAHRBACH, E., GUTT, J., HODGSON, D. A., MAYEWSKI, P. A. \& SUMMERHAYES, C. P. Antarctic Climate Change and the Environment. P. 526 pp. Cambridge, Scientific Committee on Antarctic Research. 2009

TURNER, J., COLWELL, S. R., MARSHALL, G. J., et al., Antarctic climate change during the last 50 years, International Journal of Climatology, v. 25, p. 279-294. 2005.

VAUGHAN, D. G.; MARSHALL, G. J.; CONNOLLEY, W. M.; KING, J. C.; MULVANEY, R. Climate change - devil in the detail. Science, 293, p. 1777-1779. 2001 